\title{
SIMPLE NEPHRECTOMY; ETIOLOGIES AND COMMON PRESENTATION OF NON-FUNCTIONAL KIDNEYS IN PATIENTS IN A TERTIARY CARE HOSPITAL
}

\footnotetext{
1. MBBS, FCPS

Senior Registrar, MIKD Multan.

2. MBBS, FCPS

Medical Officer, MIKD Multan.

3. MBBS, FCPS

Medical Officer, MIKD Multan.

4. MBBS, FCPS

Assistant Professor, MIKD Multan.

5. MBBS

Medical Officer, MIKD Multan.

6. MBBS

Medical Officer, MIKD Multan.
}

Correspondence Address:

Dr. Nauman Masood

Senior Registrar

Multan Institute of Kidney Diseases

Multan.

dor_nomi@yahoo.com

Article received on: 07/12/2016

Accepted for publication: $15 / 05 / 2017$

Received after proof reading: $08 / 08 / 2017$
Nauman Masood', Asif Hameed², Muhammad Iqbal Javed³ ${ }^{3}$ Ali Imran Zaidi ${ }^{4}$, Ayyaz Bilal $^{5}$, Khalid Naeem ${ }^{6}$

ABSTRACT... Objectives: The aim of this study was to identify the main etiological factors responsible for non-functional kidneys and the most common presenting complaints in patients undergoing simple nephrectomy in a tertiary care hospital. Setting: urology department of Nishter Medical College and Hospital Multan. Period: January 2014 to June 2015 were selected for this study. Methods: A total of Eighty (80) patients with non-functional kidney, who underwent simple nephrectomy. Patients of any age and gender were included. Patients having non-functional kidney due to any malignancy were excluded from this analysis. Detailed clinical history regarding pain, micturition, radiographic findings and co-morbid conditions was taken from every patients. Results: The mean patient's age was $29.21 \pm 11.80$ years and the median age was 25 years. Most common presenting complaints was flank pain. Mean Duration of flank pain was $21.86 \pm 35.06$ months. $45(56.2 \%)$ were presented with Rt. Flank pain, $29(36.2 \%)$ were presented with Lt. Flank pain and 6 (7.5\%) were of not having pain. Most common presenting complaint along with flank pain was fever presented in $19(23.8 \%)$ patients. The $2^{\text {nd }}$ most common was dysuria, 15 (8.8\%) patients were presented with flank pain+dysuria. 11 (13.8\%) were with flank pain + pyrexia. Stone disease was the most common pathology responsible for non-functional kidney diagnosed in 40 (50\%) patients, out of which 35 (43.8\%) were with renal stones and $5(6.2 \%)$ with ureteric stones. The $2^{\text {nd }}$ most common pathology was Uretero-pelvic junction obstruction (UPJO) presented in 25 (31.2\%) patients. Conclusion: Renal stones are most common benign cause responsible for most of the nephrectomies and UPJO is the $2^{\text {nd }}$ most common pathology. While most common presenting complains of patients suffering from non-functional kidney are flank pain, and flank pain along with fever or Pyuria.

Key words: $\quad$ Non-functional kidney, flank pain, nephrectomy.

Article Citation: Masood N, Hameed A, Javed MI, Zaidi Al, Bilal A, Naeem K. Simple nephrectomy; etiologies and common presentation of non-functional kidneys in patients in a tertiary care hospital. Professional Med J 2017;24(8):11101113. DOI: $10.17957 / T P M J / 17.3667$

\section{INTRODUCTION}

Like many other body organs, kidneys can also susceptible to various pathologies e.g. renal or ureteric stones, obstructive problems, infections, trauma and prostate enlargement etc. ${ }^{1}$ Nephrectomy is a treatment of choice in patients suffering from irreversible kidney diseases which may be due to stone disease, severe trauma, chronic infections, or obstructive kidney disease. ${ }^{2}$ Patients suffering from one sided kidney disorders are often unaware of the disease because of adaptive changes in the counter side kidney that results in hypertrophy and improvements in overall kidney functions. ${ }^{3}$ Patient's negligence is also a major cause of loss of unilateral kidney function. The symptoms of non-functional kidney varies from simple flank pain to complex symptoms e.g. dysuria, hematuria, pyouria, recurrent fever and even nausea or vomiting depending upon the predisposing conditions.

Kidney stone disease is common in Pakistani population. In the long run, untreated stones are a major cause of impairment of kidney functions. ${ }^{2}$ The pathophysiological processes involved in kidney impairment are chronic pyelonephritis, atrophy of parenchyma, xanthogranulomatus or in some cases renal cell carcinoma. ${ }^{4}$ Tuberculosis is also common in Pakistan and in $20 \%$ cases of extra-pulmonary tuberculosis, renal tuberculosis is identified. ${ }^{5}$ This can also lead to loss of renal function. The present aim of this study to verify 
the main etiological factors responsible for non-functional kidneys and the most common presenting complaints in patients undergoing simple nephrectomy in a tertiary care hospital.

\section{METHODS}

This study was carried out in urology department of Nishter Medical College and Hospital Multan. A total of Eighty (80) patients with non-functional kidney, who underwent simple nephrectomy from January 2014 to June 2015 were selected for this study. Patients of any age and gender were included. Patients having non-functional kidney due to any malignancy were excluded from this analysis. Detailed clinical history regarding pain, micturition, radiographic findings and co-morbid conditions was taken from every patients. The study was cross-sectional in nature.

Patients who had their kidney with paper like thin parenchyma on ultrasound with no-contrast visualization in collecting ducts on IV urography, were labelled as having non-functional kidney. ${ }^{6}$

Regarding co-morbidities there were 12 (15.0\%) hypertensive patients, 5.0 (6.2\%) diabetics, 2 $(2.5 \%)$ with history of pulmonary tuberculosis. $3(3.8 \%)$ have habit of smoking and only one patient was alcoholic.

Qualitative variable were presented as frequency along with percentages. While for quantitative variables mean and standard deviation was used for representation.

\begin{tabular}{|l|c|c|}
\hline \multicolumn{1}{|c|}{ Variable } & Frequency & Percentage \\
\hline Smoking & 3.0 & 3.8 \\
\hline Alcohol Abuse & 1.0 & 1.2 \\
\hline Hypertension & 12.0 & 15.0 \\
\hline Diabetes & 5 & 6.2 \\
\hline Ischemic Heart Disease & 4 & 5.0 \\
\hline Pulmonary Tuberculosis & 2.0 & 2.5 \\
\hline \multicolumn{2}{|c|}{ Table-I. History of Co-morbid Conditions. } \\
\hline \multicolumn{2}{|c|}{}
\end{tabular}

\section{RESULTS}

The mean patient's age was $29.21 \pm 11.80$ years and the median age was 25 years. There were equal number of male and female in this study. Mean pre-operative urea levels were $26.7 \pm 8.77$ $\mathrm{mg} / \mathrm{dl}$ and the creatinine levels were $0.96 \pm 0.38$ $\mathrm{mg} / \mathrm{dl}$. Mean Total Leukocyte (TLC) levels were $9.79+2.84 \square 10^{3} / \mathrm{L}$. Mean Duration of flank pain was $21.86 \pm 35.06$ months and median age was 4 months. 45 (56.2\%) were presented with Rt. Flank pain, 29 (36.2\%) were presented with Lt. Flank pain and $6(7.5 \%)$ were of not having pain and were presented with other symptoms (Table-II).

Most common presenting complaint along with flank pain was fever. 19 (23.8\%) patients were presented with flank pain + fever. The $2^{\text {nd }}$ most common was dysuria, 15 (8.8\%) patients were presented with flank pain + dysuria. 11 (13.8\%) were with flank pain + pyrexia. In 5 (6.2\%) patients hematuria was the presenting complain along with flank pain. And Chr. Sinus discharge from flank along with flank pain was present in only $2(2.5 \%)$ patients (Figure-1).

The most common pathology responsible for non-functional kidney was stones which were present in 40 (50\%) patients, out of which 35 (43.8\%) were with renal stones and $5(6.2 \%)$ with ureteric stones. The $2^{\text {nd }}$ most common pathology was Uretero-pelvic junction obstruction (UPJO) which was present in 25 (31.2\%) patients. The other pathologies were Chr. Pyelonephritis present in 5 (6.2\%) patients and tuberculous pyelonephritis which was present in only $1(1.2 \%)$ patient (Figure-2).

\begin{tabular}{|c|c|c|}
\hline \multicolumn{2}{|c|}{ Name of Variable } & Value \\
\hline \multicolumn{2}{|c|}{ Age of Patients (Y) (Mean+S.D.) } & $29.21 \pm 11.80$ \\
\hline \multicolumn{2}{|l|}{ Median } & 25 \\
\hline \multirow[t]{2}{*}{ Gender (\%) } & Male & $40(50.0)$ \\
\hline & Female & $40(50.0)$ \\
\hline \multicolumn{2}{|c|}{ Urea mg/dl (Mean+S.D.) } & $26.7 \pm 8.77$ \\
\hline \multicolumn{2}{|c|}{ Creatinine $\mathrm{mg} / \mathrm{dl}$ (Mean+S.D.) } & $0.96 \pm 0.38$ \\
\hline $\begin{array}{l}\text { Total Leukocyte } \\
\text { (Mean+S.D.) }\end{array}$ & Count $\quad \times 10^{3} / L$ & $9.79 \pm 2.84$ \\
\hline \multirow{3}{*}{ History of Pain (\%) } & Rt. Flank Pain & 45 (56.2) \\
\hline & Left Flank Pain & $29(36.2)$ \\
\hline & No Pain & $6(7.5 \%)$ \\
\hline \multicolumn{2}{|c|}{ Duration of Flank Pain (Mean+S.D.) } & $21.86 \pm 35.06$ \\
\hline
\end{tabular}




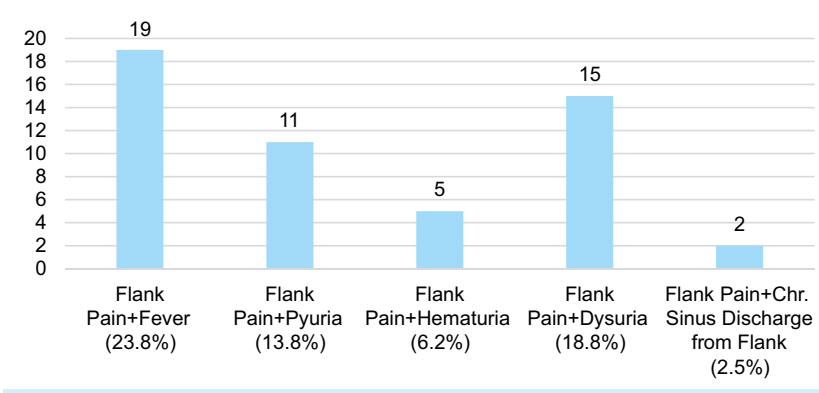

Figure-1. Common Presenting Complaints of Patients other than Flank Pain.

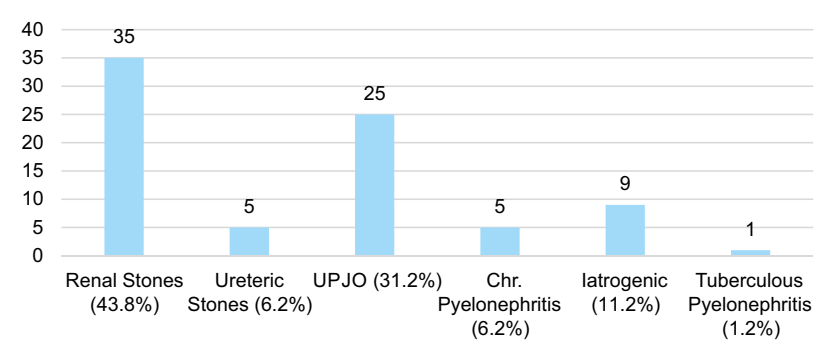

Figure-2. Common Pathologies Responsible for NonFunctional Kidney.

\section{DISCUSSION}

The number of nephrectomies due to benign pathologies is decreasing day by day in the modern world in comparison with the malignant pathologies. ${ }^{7,8}$ But in developing countries most of the nephrectomies are still performed due to benign conditions. In some researches this rate has been reported to be $70-76.6 \%$. $^{2,9}$ This decline in developed countries may be due to better management of urinary tract infection, renal stones, hypertension and other benign conditions.

Delayed referral is also a main cause of nephrectomies due to benign reasons in developing countries. In our study, the mean referral time was $21.86 \pm 35.06$ months after the development of flank pain and other symptoms. In our study, 92.4\% patients were presented with unilateral flank pain and $7.6 \%$ with bilateral flank pain. $23.8 \%$ patients were presented with fever along with flack pain and $13.8 \%$ with pyuria. In a study by Rafique et al, flank pain was mostcommon presentation, presented in $72.0 \%$ patients, and flank pain plus fever in $5.0 \%$ patients. ${ }^{10}$ In study by Bangash, $2.9 \%$ patients were presented with bilateral flank pain, $2.9 \%$ with flank pain plus fever and $10.7 \%$ with flank pain plus pyuria. ${ }^{11}$ The frequency of presenting complaints were different in our study as compared to the other studies.

In this study, the main cause of non-functional kidneys were stones (ureteric and renal), which were present in $50 \%$ of all nephrectomies. In Pakistan, the reported incidence of renal stone disease in patients undergoing simple nephrectomy is $53.3 \%$ to $54.4 \% \%^{2,11}$ But in a study from association of urological surgeon's nephrectomy database, renal stone disease was responsible for only $13.0 \%$ case of nephrectomy due to benign reasons. ${ }^{11}$ It means that untreated renal stones are the main cause of nephrectomy in our patient population. The risk of renal stone disease is two-three times higher in males as compared to their female counterpart according to some studies. ${ }^{10,13}$ But in our study, there were $21(52.5 \%)$ females and $19(47.5 \%)$ males who were diagnosed of having renal stone disease. Rafique $\mathrm{M}$ also reported higher rate of female counter part in his study. ${ }^{2}$ In that study, there were 37 females and 24 males who underwent nephrectomy. In the previous trials, the rate of nephrectomy due to renal tuberculosis has been reported to be 2.4-7.0\%.7,9,11 In present study, renal tuberculosis was responsible for $1.2 \%$ of total nephrectomy. This rate is less as compared to other studies. In our study, the $2^{\text {nd }}$ most common reason of nephrectomy was Ureteropelvic junction obstruction (UPJO) that accounted for $31.2 \%$ of total non-functional kidneys. While in other studies the reported rate of UPJO was $16.0-20.4 \%$, this rate was significantly less as compared to our study.

So, renal stones and UPJO are most common pathologies in patients undergoing simple nephrectomy and Flank pain plus fever and Flank pain plus Pyuria are most common presenting complaints according to the results of this study.

\section{CONCLUSION}

Renal stones are most common benign cause responsible for most of the nephrectomies and UPJO is the $2^{\text {nd }}$ most common pathology. While most common presenting complains of patients 
suffering from non-functional kidney are flank pain, and flank pain along with fever or Pyuria.

Copyright@ 15 May, 2017.

\section{REFERENCES}

1. Datta B, Moitra T, Chaudhury DN, Halder B. Analysis of 88 nephrectomies in a rural tertiary care center of India. Saudi Journal of Kidney Diseases and Transplantation. 2012;23(2):409.

2. Rafique M. Nephrectomy: indications, complications and mortality in 154 consecutive patients. JPMA. 2007.

3. Gluhovschi G, Gadalean F, Gluhovschi C, Petrica L, Velciov S, Gluhovschi A, et al. The solitary kidney-a nephrological perspective. Rom J Intern Med. 2013;51(2):80-8.

4. Shah HN, Jain $P$, Chibber PJ. Laparoscopic nephrectomy for giant staghorn calculus with nonfunctioning kidneys: Is associated unsuspected urothelial carcinoma responsible for conversion? Report of 2 cases. BMC urology. 2006;6(1):1.

5. Binayke R, Sisodia S. Tuberculosis and incidental tubulopapillary adenoma in a nephrectomy specimen. Bombay Hosp J. 2011;53(2):223-5.

6. Zengin K, Tanik S, Sener NC, Albayrak S, Ekici M, Bozkurt IH, Bakirtas H, Gurdal M, Imamoglu MA. Incidence of renal carcinoma in non-functioning kidney due to renal pelvic stone disease. Molecular and clinical oncology. 2015 Jul 1;3(4):941-3.
7. Beisland C, Medby PC, Sander S, Beisland HO. Nephrectomy-indications, complications and postoperative mortality in 646 consecutive patients. European urology. 2000;37(1):58-64.

8. Eke N, Echem R. Nephrectomy at the University of Port Harcourt Teaching Hospital: a ten-year experience. African journal of medicine and medical sciences. 2003;32(2):173-7.

9. Ghalayini IF. Pathological spectrum of nephrectomies in a general hospital. Asian Journal of Surgery. 2002;25(2):163-9.

10. Rafique M, Bhutta RA, Rauf A, Chaudhry IA. Chemical Composition of Upper Renal Tract Calculi in Mutan. Journal-Pakistan Medical Association. 2000;50(5):1457.

11. Bangash K, Alam A, Amin M, Anwar K. The Knocked-out Unilateral Kidney! Causes and Presentation. Journal of Ayub Medical College Abbottabad. 2015;27(3):656-9.

12. Zelhof B, Mclntyre IG, Fowler SM, Napier $\square$ Hemy RD, Burke DM, Grey BR. Nephrectomy for benign disease in the UK: results from the British Association of Urological Surgeons nephrectomy database. BJU international. 2016;117(1):138-44.

13. Bangash K, Shigri F, Jamal A, Anwar K. Spectrum of renal stones composition: chemical analysis of renal stones. International Journal of Pathology. 2011;9(2):636.

\section{AUTHORSHIP AND CONTRIBUTION DECLARATION}

\begin{tabular}{|c|l|l|}
\hline Sr. \# & \multicolumn{1}{|c|}{ Author-s Full Name } & \multicolumn{1}{|c|}{ Contribution to the paper } \\
\hline 1 & Dr. Nauman Masood & Main Author \\
2 & Dr. Asif Hameed & Co-author \\
3 & Dr. Muhammad lqbal Javed & Co-author \\
4 & Dr. Ali Imran Zaidi & Co-author \\
5 & Dr. Ayyaz Bilal & Co-author \\
6 & Dr. Khalid Naeem & Co-author
\end{tabular}

